\title{
Comparing very low birth weight versus very low gestation cohort methods for outcome analysis of high risk preterm infants
}

Louise IM Koller-Smith', Prakesh S. Shah' ${ }^{2,3}$, Xiang Y. Ye ${ }^{3}$, Gunnar Sjörs ${ }^{4}$, Yueping A. Wang ${ }^{1}$, Sharon S. W. Chow ${ }^{1}$, Brian A. Darlow ${ }^{5}$, Shoo K. Lee ${ }^{2,3}$, Stellan Håkanson ${ }^{6}$, Kei Lui ${ }^{1,7^{*}}$, on behalf of the Australian and New Zealand Neonatal Network, Canadian Neonatal Network and Swedish Neonatal Quality Register

\begin{abstract}
Background: Compared to very low gestational age ( $<32$ weeks, VLGA) cohorts, very low birth weight ( $<1500$ g; VLBW) cohorts are more prone to selection bias toward small-for-gestational age (SGA) infants, which may impact upon the validity of data for benchmarking purposes.

Method: Data from all VLGA or VLBW infants admitted in the 3 Networks between 2008 and 2011 were used. Two-thirds of each network cohort was randomly selected to develop prediction models for mortality and composite adverse outcome (CAO: mortality or cerebral injuries, chronic lung disease, severe retinopathy or necrotizing enterocolitis) and the remaining for internal validation. Areas under the ROC curves (AUC) of the models were compared.
\end{abstract}

Results: VLBW cohort (24,335 infants) had twice more SGA infants (20.4\% vs. 9.3\%) than the VLGA cohort (29,180 infants) and had a higher rate of CAO (36.5\% vs. 32.6\%). The two models had equal prediction power for mortality and CAO (AUC 0.83), and similarly for all other cross-cohort validations (AUC 0.81-0.85). Neither model performed well for the extremes of birth weight for gestation ( $<1500 \mathrm{~g}$ and $\geq 32$ weeks, AUC $0.50-0.65 ; \geq 1500 \mathrm{~g}$ and $<32$ weeks, AUC 0.60-0.62).

Conclusion: There was no difference in prediction power for adverse outcome between cohorting VLGA or VLBW despite substantial bias in SGA population. Either cohorting practises are suitable for international benchmarking.

Keywords: Outcome, Intensive care, Neonatal, Infant, Premature, Very low birth weight, Small for gestational age, Benchmarking

\section{Background}

Very premature and very low birth weight (VLBW) infants are at high risk of mortality and morbidities. Effective outcome prediction and benchmarking, for parental counseling, quality improvement and informing the wider community, have their foundation in the outcome statistics of infant cohorts [1]. There are two established methods of cohorting high-risk infants, by

\footnotetext{
* Correspondence: k.lui@unsw.edu.au

${ }^{1}$ Faculty of Health Science, University of Technology Sydney, Sydney, NSW, Australia

${ }^{7}$ Department of Newborn Care, Royal Hospital for Women, Barker St, Sydney, NSW 2031, Australia

Full list of author information is available at the end of the article
}

birth weight (for example, VLBW, $<1500 \mathrm{~g}$ ) or by gestational age (for example, very low gestational age [VLGA], $<32$ weeks), with the relative advantages of each yet to be determined. There has been increasing acceptance of gestational age (GA) based cohorting in recent literature [2-5], following studies such as that by Arnold et al. in 1991 [6] and Blair et al. in 1996 [6, 7], which raised concerns that VLBW cohorts may be inherently biased.

Birth weight (BW) is dependent on two separate influences; GA at birth and fetal growth rate [8]. It follows that a VLBW cohort may contain infants at any point along a spectrum from very preterm and sized appropriately for their GA (AGA) to small for gestational age (SGA). There is an inherent selection bias toward SGA 
infants in VLBW cohorts, which becomes more pronounced at higher gestations, as the birth weights of AGA infants become greater than $1500 \mathrm{~g}[6,7,9]$. This disproportionate SGA percentage is exemplified in published studies that have used VLBW cohorts, wherein $19 \%$ to $40 \%$ of infants were SGA [10-14]. A skewing of risk toward poorer outcome would be expected even in multivariate analyses because high-risk SGA infants lack an equivalent AGA control for adjustment within the cohort. In comparison, GA is independent of BW and fetal growth rate [7], and hence fetal growth and BW for GA show a normal distribution in VLGA cohorts [6]. SGA proportion, by definition, will remain close to $10 \%$ across all published cohorts, where SGA percentage ranged from $9.2-12 \%[15,16]$.

Meaningful international examination of neonatal outcomes is currently limited by the variations in reporting between nations [17], as direct comparison of neonatal outcomes through benchmarking requires prior standardization of the infant cohorting method used for data collection and reporting. The World Health Organization changed its standard cohorting practice to GA-based in 1961 [18], but some studies and analyses persist in the use of BW criteria [1, 19-21].

The overall aim of this study was to evaluate and compare the predictive power of prediction models developed using VLGA and VLBW-based cohorts. It was hypothesized that predictive power of the VLGA-based models would be significantly better than that of the VLBW-based models across all networks because it would reduce the selection bias introduced by the disproportionately high number of SGA infants.

\section{Methods}

De-identified clinical data were obtained from the Australian and New Zealand Neonatal Network (ANZNN), Canadian Neonatal Network (CNN) and Swedish Neonatal Quality Register (SNQ) for all infants born either at $<32$ weeks gestational age or with birth weights $<1500 \mathrm{~g}$, who were admitted to participating NICUs in between January 2008 and December 2011. Networks were selected because of their intrinsic similarity, with comparable demographics and healthcare systems. All three networks have the registration criteria for data collection if admitted infants are either $<32$ weeks or $<1500 \mathrm{~g}$. Infants were also excluded if they were moribund (died within the first day of admission without being offered mechanical ventilation or intensive care) or had major congenital anomalies.

The parameters for data collection in each of the network databases were compared. Definitions of outcomes and variables to be analyzed were standardized by consensus a priori. National preterm BW percentiles were examined for each network, and found to be very similar in Australia [22] and Canada [23], however in-utero growth charts were used in the SNQ [24], and therefore the Swedish percentiles were not comparable. For this reason, Canadian BW percentile charts were applied to all infants to define SGA and BW z score.

For the study period, ANZNN data comprised all 29 tertiary hospitals in Australia/New Zealand; CNN comprised 28 of 30 tertiary hospitals in Canada; and SNQ all 25 hospitals with neonatal units in 6 of the 7 health care regions of Sweden. Study data were available through the iNeo (International Network for Evaluating Outcomes in Neonates) project housed at Mother-Infant Care Research Center, Mount Sinai Hospital, University of Toronto, Canada.

The primary outcome studied was in-hospital mortality. The secondary outcome was composite adverse outcome (CAO), defined as in-hospital mortality or a pre-discharge diagnosis of any major neonatal morbidities of chronic lung disease (CLD), serious neurological injuries (SNI) including intraventricular hemorrhage grade III or IV [25] or periventricular leukomalacia, severe retinopathy of prematurity stage 3 or more (ROP) [26] and radiologically or pathologically proven necrotizing enterocolitis (NEC) [27], Consensus outcome definitions are provided in Additional file 1: Table S1. Nosocomial infection was not included in CAO but was included in descriptive analyses, as rate of NI may be used as a marker of patient safety and healthcare effectiveness and outcomes, and hence has relevance for comparison between international cohorts [28].

Data from all networks were amalgamated and formed into two overlapping cohorts of infants less than 32 weeks (VLGA) and/or less than $1500 \mathrm{~g}$ (VLBW). Originating network was added as a covariate for subsequent analysis. Of the two overlapping VLBW and VLGA cohorts, two-thirds (balanced for network) were randomly selected, using a split sample method [29], to form the derivation samples for development of two prediction models. The remaining one-third of infants from each cohort formed the internal validation samples, for assessment of predictive power on independent samples.

Prediction models were developed for mortality and $\mathrm{CAO}$ by multivariable logistic regression with backwards procedures using exclusion criteria of 0.05 , according to methodology validated in previous population studies $[30,31]$. The interaction of BW z-score and GA was also included as a covariate in multivariable analysis to adjust for the varying confounding effects of growth status and maturity.

Analysis for prediction power was conducted for each model on both the VLGA and the VLBW validation samples, which consisted of the VLBW and VLGA validation samples, and two mutually exclusive "extreme" subcomponents of infants $<1500 \mathrm{~g}$ but $\geq 32$ weeks, and infants $<32$ weeks but $\geq 1500$ g. Prediction power was 
assessed using area under the Receiver Operating Characteristic (ROC) curve [32-34]. An AUC of $>0.80$ is generally accepted as excellent prediction [35]. AUC of each prediction was compared. Goodness-of-fit was determined by use of the Hosmer-Lemeshow test [13] to test for systematic over or underestimation of outcomes by the model [36]. Data management and analyses were performed using SAS 9.3 [37] and R 2.10.15 [38]. A twosided significance level of 0.05 has been used without adjustment for multiple comparisons.

ANZNN data collection, access and use of deidentified data for audit and research was approved by all relevant institutional research ethics committees of each NICU hospital (see list of hospitals in Acknowledgement) in Australia, and by the New Zealand Multiregional Ethics Committee for all the New Zealand hospitals listed. For the $\mathrm{CNN}$ and SNQ, de-identified data collection was approved at each site by either an institutional ethics board or quality improvement committee of the hospitals listed. All participating networks have obtained ethics/regulatory approval or the equivalent from their local granting agencies to allow for de-identified data to be collated. De-identified ANZNN, $\mathrm{CNN}$ and SNQ data were amalgamated at the iNeo collaboration centre where analysis occurred. Approval for this project was obtained from the South Eastern Sydney Local Health District Human Research Ethics Committee and approval for data transfer was obtained from all three networks executive committees. The ethics committees waived the requirement for the consent. Data from all networks were amalgamated and used for this study.

The Coordinating Centre has been granted Research Ethics Board approval for the development, compilation, and hosting of the dataset, and all 3 networks have signed data transfer agreements with the Coordinating Centre. Privacy and confidentiality of patient and unitrelated data will be of prime importance to the iNeo collaboration, and data collection, handling, and transfer will be performed in accordance with the Canadian Privacy Commissioner's guidelines, the Personal Information Protection and Electronic Documents Act, and any other local rules and regulations. No data identifiable at the patient level will be collected or transmitted, and only aggregate data will be reported. For all stages of the project, participating units will be assigned a code by their own network prior to data transfer into the iNeo dataset so that units remain anonymous within the iNeo collaborative. Following data analysis, findings will be disseminated within networks by their own network coordination team and not by the iNeo central team.

Following completion of the study in 2017, the data will be kept at the iNeo Coordinating Centre for a further 2 years before being returned to the originating networks unless otherwise agreed by the member networks.

\section{Results}

The derivation of the study cohort is detailed in Fig. 1. The final study population contained 31,940 infants; 14,954 infants from the ANZNN (46.8\%), 13,297 (41.6\%) from the CNN and 3689 (11.5\%) from the SNQ. The VLBW cohort was made up of 24,335 infants $(76.2 \%$ of study population) and the VLGA cohort of 29,180 infants (91.4\% of study population).

The majority of infant characteristics were similar between the VLGA and VLBW cohorts (see Table 1), with the expected exception of SGA percentage, which was more than double in the VLBW cohort (20.4\%) compared to the VLGA cohort (9.3\%). For the VLGA cohort, mean GA was marginally higher for ANZNN infants (28.5 weeks) than for CNN or SNQ infants (28.3 weeks). Antenatal steroid use was significantly lower in the CNN than ANZNN and SNQ. Significantly fewer infants required exogenous surfactant in the ANZNN than CNN or SNQ. Similar disparities between networks were seen in the VLBW cohort.

\section{Neonatal outcomes}

In the VLGA cohort (Table 1), mortality rates were similar across networks while $\mathrm{CAO}$ was higher in the $\mathrm{CNN}$ (36.5\%) than the ANZNN (28.7\%) and SNQ (30.3\%). The same trends were observed in the VLBW cohort. Mortality rates were similar between the VLBW (8.9\%) and VLGA (7.7\%) cohorts. The greatest disparity was in the higher rates of CLD $(21.7 \%$ vs. $19.2 \%)$ and NI $(18.1 \%$ vs. $16.0 \%)$ in the VLBW cohort. CAO rate was higher $(36.5 \%$ vs. $32.6 \%)$ in the VLBW cohort, beyond the effect of the increased CLD incidence. The neonatal outcomes of all 3 networks stratified by gestation subgroups (22-24, 25-26, 27-28 and 29-31 weeks) and birth weight $(<750 \mathrm{~g}, 750-999 \mathrm{~g}, 1000-1249 \mathrm{~g}$ and 1250-1499 g) subgroups are summarised in Additional file 1: Table 2 (a) and (b).

\section{VLGA and VLBW prediction models for mortality and composite adverse outcome}

Mortality prediction models developed using the VLBW and VLGA derivation cohorts are shown in Table 2 . AUC was analogous for the VLBW (0.830) and VLGA (0.828) based models, and both models had equally good discriminatory power. The CAO prediction models (Table 3) included similar variables to the mortality prediction models. Both the VLGA and VLBWbased models showed equal discrimination, with an AUC of 0.83 . 


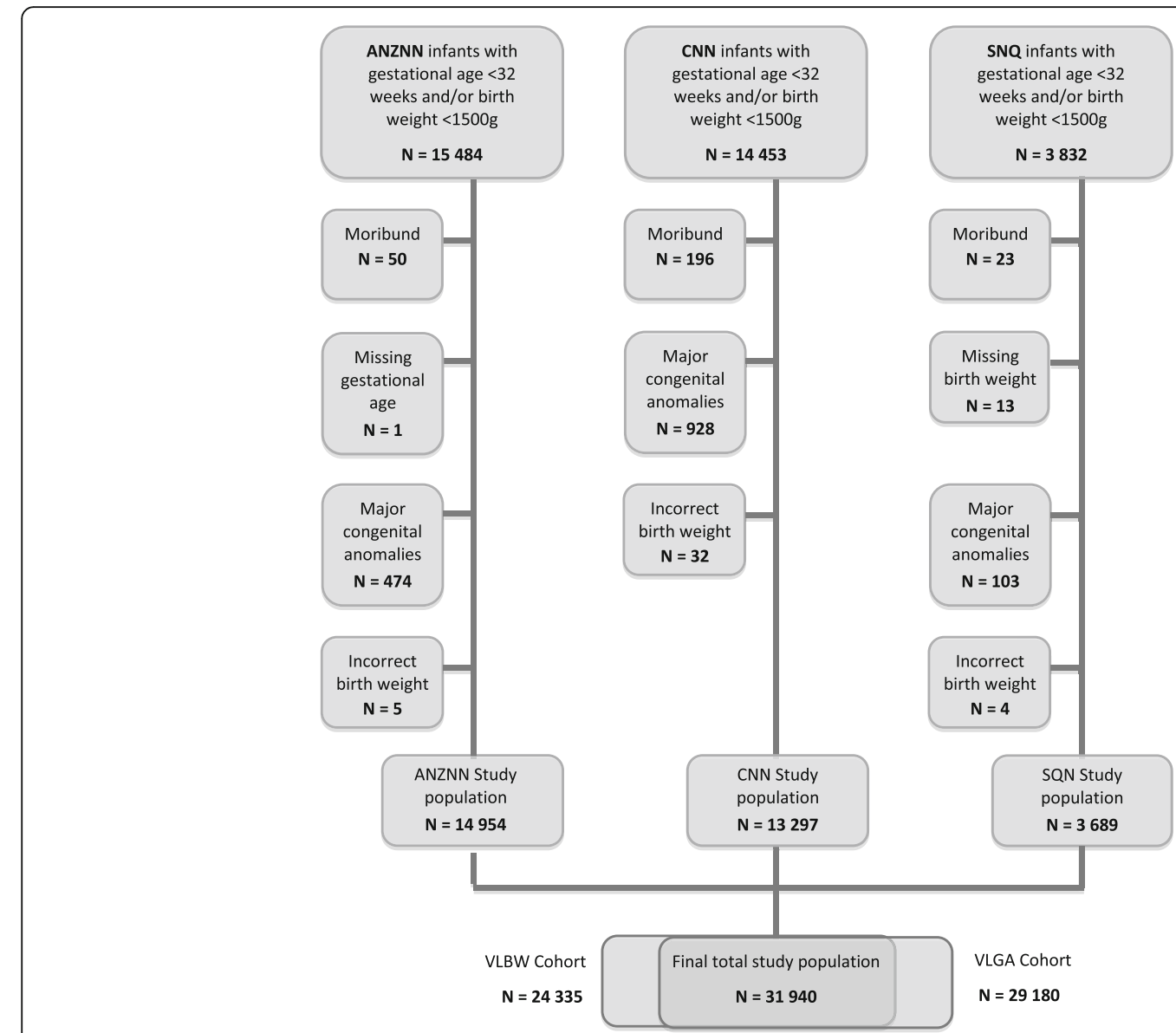

Fig. 1 Flow Chart of Study Cohort: derivation of the study infants from each neonatal network is summarised

\section{Application of prediction models to validation samples} When applied to the validation samples, the predictive power of both the VLBW-based and VLGA- based models remained excellent (AUC 0.81-0.85) for prediction of mortality and CAO. Cross-comparison showed equivalent performance between the VLBW and VLGA-based models for application to both the VLBW and VLGA developmental samples (Additional file 1: Table 3). Statistical significance $(p<0.05)$ was reached between the VLGA and VLBW-based CAO prediction models for the VLBW validation sample. Predictive power of the VLBW and VLGA-based models remained excellent across networks and exhibited a narrow range in AUC of 0.81 to 0.86 . This demonstrated the applicability of the developed models to the three included networks. Due to the large sample sizes, statistical significance was shown between the VLGA and VLBW models for some comparisons despite very small differences.

\section{Application of prediction models to extreme subsets}

There are two mutually exclusive subset of the cohorts: 2759 infants in the VLBW cohort whose gestation was 32 weeks or above and 7603 infants in the VLGA cohort whose birthweight was 1500 g or more. Predictive power decreased when the models were applied to these two extreme subset of the VLBW and VLGA cohorts (AUC 0.50-0.62) (Table 4). Neither model demonstrated consistently better performance for the prediction of mortality or CAO in either of the extreme subsets. In the VLBW and $\geq 32$ week extreme subsets, most (2273/2759, $82.4 \%)$ were SGA, and conversely in the extreme VLGA and $\geq 1500$ g subset a smaller proportion (713/7603, 9.3\%) were SGA and a considerable number of infants (1300/7603, 17.1\%) were large for gestation age (LGA). Both extreme subsets had consistently lower crude morbidity and composite adverse outcome rates than those of the total cohorts (Additional file 1: Table 4).

\section{Discussion}

This study is the first to systematically assess the comparative predictive power of VLBW and VLGA cohorting methods. Belief in the superiority of gestation-based cohorts has grown amongst many investigators [2, 3, 39-41] in response to suggestion that VLBW cohorts are limited by their innate confounding of growth status and maturity $[6-8,17,42]$, but have not been formally validated. In this 
Table 1 Comparisons of infant and perinatal characteristics and neonatal outcomes among networks (ANZNN, CNN, SNQ) for very low gestational age cohort and very low birth weight cohort derived from network admissions 2008-2011

\begin{tabular}{|c|c|c|c|c|c|c|c|c|}
\hline \multirow[b]{2}{*}{ Networks } & \multicolumn{4}{|c|}{ Very low gestational age } & \multicolumn{4}{|c|}{ Very low birth weight } \\
\hline & ANZNN & CNN & SNQ & $P$-value & ANZNN & CNN & SNQ & $P$-value \\
\hline Total number & 13,586 & 12,167 & 3427 & & 11,307 & 10,327 & 2701 & \\
\hline \multicolumn{9}{|l|}{ Infant and Perinatal Characteristics } \\
\hline Gestational age, mean(SD) & $28.5(2.2)$ & $28.3(2.2)$ & $28.3(2.4)$ & $<0.0001$ & $28.3(2.6)$ & $28.2(2.6)$ & $27.9(2.7)$ & $<0.0001$ \\
\hline Birth weight, mean(SD) & $1232396)$ & $1209(387)$ & $1234(424)$ & $<0.0001$ & $1082(274)$ & $1068(267)$ & $1055(291)$ & $<0.0001$ \\
\hline Male sex & $7345(54.1)$ & $6617(54.5)$ & $1838(53.6)$ & 0.6619 & $5762(51.0)$ & $5290(51.3)$ & $1372(50.8)$ & 0.8571 \\
\hline Small for gestational age & $1249(9.2)$ & $1133(9.3)$ & $317(9.3)$ & 0.9515 & $2369(21.0)$ & 2082(20.2) & $521(19.3)$ & 0.0999 \\
\hline Singleton & $9532(70.2)$ & $8417(69.3)$ & $2441(71.3)$ & 0.0478 & $7901(69.9)$ & $7099(68.8)$ & $1930(71.5)$ & 0.016 \\
\hline Surfactant required & $7336(54.1)$ & 7179 (59.0) & $1941(56.8)$ & $<0.0001$ & $6442(57.1)$ & $6233(60.4)$ & 1649 (61.3) & $<0.0001$ \\
\hline Antenatal steroid use & $12,902(95.1)$ & $10,156(86.6)$ & $3278(95.7)$ & $<0.0001$ & $10,723(95.0)$ & $8520(85.7)$ & 2581 (95.6) & $<0.0001$ \\
\hline Caesarean & $8478(62.7)$ & $7117(59.0)$ & $2086(61.2)$ & $<0.0001$ & $7311(65.0)$ & $6565(64.1)$ & $1679(62.7)$ & 0.0613 \\
\hline Presentation (vertex) & $8676(65.4)$ & $7307(64.7)$ & $2209(65.7)$ & 0.3872 & 7099 (64.2) & $6004(63.0)$ & $1720(65.3)$ & 0.0353 \\
\hline Maternal age, mean(SD) & $29.8(6.4)$ & $30.5(5.9)$ & $29.9(6.5)$ & $<0.0001$ & $29.7(6.5)$ & $30.5(6.0)$ & $29.8(6.6)$ & $<0.0001$ \\
\hline \multicolumn{9}{|l|}{ Neonatal Outcomes } \\
\hline Mortality & $987(7.3)$ & $986(8.1)$ & $265(7.7)$ & 0.0407 & $948(8.4)$ & $945(9.2)$ & $252(9.3)$ & 0.0841 \\
\hline Severe neurological injury & 758 (5.6) & $1409(9.4)$ & $220(6.4)$ & $<0.0001$ & $711(6.3)$ & 1293(10.1) & $202(7.5)$ & $<0.0001$ \\
\hline Severe retinopathy of prematurity & $496(3.7)$ & $592(4.9)$ & $146(4.3)$ & $<0.0001$ & $487(4.3)$ & $596(5.8)$ & $144(5.3)$ & $<0.0001$ \\
\hline Necrotising enterocolitis & $591(4.4)$ & $690(5.7)$ & $143(4.2)$ & $<0.0001$ & $566(5.0)$ & $641(6.2)$ & $134(5.0)$ & 0.0002 \\
\hline Chronic lung disease & $2381(17.5)$ & $2597(21.3)$ & $629(18.4)$ & $<0.0001$ & $2233(19.8)$ & 2472(23.9) & $586(21.7)$ & $<0.0001$ \\
\hline Composite adverse outcome & $3893(28.7)$ & $4564(36.5)$ & $1043(30.4)$ & $<0.0001$ & 3649 (32.3) & $4272(40.3)$ & $962(35.6)$ & $<0.0001$ \\
\hline Nosocomial Infection & $2008(14.8)$ & $2188(18.0)$ & $484(14.1)$ & $<0.0001$ & $1869(16.5)$ & $2069(20.0)$ & $454(16.8)$ & $<0.0001$ \\
\hline
\end{tabular}

$\mathrm{N}(\%)$ are shown unless specified

Notes: the reported $p$-values were based on chi-square tests for categorical variables, and $\mathrm{F}$ tests for continuous variables. Composite adverse outcome is defined as: death or any major morbidities including chronic lung disease, severe neurological injury, necrotising enterocolitis, severe retinopathy. Nosocomial infection is not included

Table 2 Predictive models for mortality developed using data from ANZNN, CNN and SNQ 2008-2011

\begin{tabular}{|c|c|c|c|c|c|c|}
\hline \multirow[b]{2}{*}{ Covariates } & \multicolumn{3}{|c|}{ (a) Model based on BW cohort } & \multicolumn{3}{|c|}{ (b) Model based on GA cohort } \\
\hline & Estimate & SE & $P$-value & Estimate & SE & $P$-value \\
\hline Intercept & 14.1797 & 0.4661 & $<0.0001$ & 12.9809 & 0.3814 & $<0.0001$ \\
\hline GA (weeks) & -0.6128 & 0.0182 & $<0.0001$ & -0.5629 & 0.0146 & $<0.0001$ \\
\hline BW z score & 1.5657 & 0.3677 & $<0.0001$ & $\#$ & & \\
\hline GA x BW z score & -0.067 & 0.014 & $<0.0001$ & $\#$ & & \\
\hline Country (Sweden vs CA) & $\#$ & & & \# & & \\
\hline Country (Australia vs CA) & $\#$ & & & $\#$ & & \\
\hline Gender (male) & 0.3499 & 0.0642 & $<0.0001$ & 0.2969 & 0.0616 & $<.0001$ \\
\hline Antenatal steroid use & -0.6825 & 0.104 & $<0.0001$ & -0.5745 & 0.1008 & $<.0001$ \\
\hline Singleton & \# & & & \# & & \\
\hline Cesarean & $\#$ & & & $\#$ & & \\
\hline Presentation (Vertex) & -0.1562 & 0.0639 & 0.015 & -0.2213 & 0.0611 & 0.0003 \\
\hline Area under ROC curve & 0.8303 & 0.0058 & & 0.828 & 0.00585 & \\
\hline Hosmer-Lemeshow test & & & 0.18 & & & 0.15 \\
\hline
\end{tabular}

Multiple logistic regression models were applied to obtain the final predictive models using stepwise variable selection procedure with inclusion and exclusion criterion of 0.05 ; \# excluded by the variable selection procedure

Notes: $B W$ z score Birth weight z score, GA x BW z score interaction between GA and Birth weight z score, Estimate estimated coefficient of the covariate, SE standard error 
Table 3 Predictive models for composite adverse outcome developed using data from ANZNN, CNN and SNQ 2008-2011

\begin{tabular}{|c|c|c|c|c|c|c|}
\hline \multirow[b]{2}{*}{ Covariates } & \multicolumn{3}{|c|}{ (a) Model based on BW cohort } & \multicolumn{3}{|c|}{ (b) Model based on GA cohort } \\
\hline & Estimate & SE & $P$-value & Estimate & SE & $P$-value \\
\hline Intercept & 18.66 & 0.363 & $<0.0001$ & 17.8 & 0.285 & $<0.0001$ \\
\hline GA (weeks) & -0.682 & 0.013 & $<0.0001$ & -0.649 & 0.01 & $<0.0001$ \\
\hline BW z score & 1.386 & 0.272 & $<0.0001$ & -0.15 & 0.022 & $<0.0001$ \\
\hline GA $\times$ BW z score & -0.057 & 0.01 & $<0.0001$ & \# & & \\
\hline Country (sweden vs CA) & -0.427 & 0.07 & $<0.0001$ & -0.326 & 0.065 & $<0.0001$ \\
\hline Country (Australia vs CA) & -0.416 & 0.045 & $<0.0001$ & -0.371 & 0.042 & $<0.0001$ \\
\hline Gender (male) & 0.192 & 0.042 & $<0.0001$ & 0.257 & 0.039 & $<0.0001$ \\
\hline Antenatal steroid use & -0.259 & 0.08 & 0.0012 & -0.237 & 0.075 & 0.002 \\
\hline Singleton & $\#$ & & & $\#$ & & \\
\hline Cesarean & 0.3 & 0.044 & $<0.0001$ & 0.241 & 0.04 & $<0.0001$ \\
\hline Presentation (Vertex) & $\#$ & & & $\#$ & & \\
\hline Area under ROC curve & 0.837 & 0.0033 & & 0.835 & 0.003 & \\
\hline Hosmer-Lemeshow test & & & 0.19 & & & 0.373 \\
\hline
\end{tabular}

Multiple logistic regression models were applied to obtain the final predictive models using stepwise variable selection procedure with inclusion and exclusion criterion of $0.05 ; \#=$ excluded by the variable selection procedure

Notes: BW z score Birth weight z score, GA x BW z score interaction between GA and Birth weight z score, Estimate estimated coefficient of the covariate, SE standard error

retrospective population study of 31,940 neonates from Australia/New Zealand, Canada and Sweden, we identified that outcome prediction models derived from VLGA and VLBW cohorts perform equally well for prediction of inhospital mortality and $\mathrm{CAO}$ in these high-risk preterm infants.

As expected, the VLBW study cohort held a disproportionately high number of SGA infants $[6-8,17,42]$ in harmony with previous large population studies, which show SGA proportions of $20-39 \%$ in VLBW groups $[10-13,43,44]$ compared to $8-12 \%$ in VLGA groups $[15,16,45-47]$.

The expected skewing of risk toward poor outcome in VLBW cohorts was confirmed by the higher rate of CAO in this group (36.5\%) compared to the VLGA group (32.6\%). The VLBW study cohort had higher rates of NI (18.1\% vs. $16.0 \%)$ and CLD (21.7\% vs. $19.2 \%)$ than

Table 4 Cross comparison of predictive power of the very low birth weight (VLBW) and very low gestational age (VLGA) based prediction models for application to the total extreme subsets of the VLGA and VLBW verification cohorts

\begin{tabular}{lll}
\hline Extreme subsets & BW $<1500$ & GA <32 \\
& $\& G A \geq 32$ wk & $\& B W \geq 1500$ \\
& $n=893$ & $n=2527$ \\
\hline Model for mortality based on VLBW cohort & 0.605 & 0.623 \\
Model for mortality based on VLGA cohort & 0.504 & 0.618 \\
Model for CAO based on VLBW cohort & 0.649 & $0.608 \neq$ \\
Model for CAO based on VLGA cohort & 0.618 & $0.622 \neq$ \\
\hline
\end{tabular}

Notes: t: $p<0.01, \neq: p<0.05$; Two figures are significantly different if they share the same symbol. Chi-square test was used for the comparison in predictive power of the two models the VLGA cohort across all networks [48] confirming previous studies that SGA infants have higher risk of CLD [49-53] and NI [50, 52, 54] compared to AGA infants of the same GA. Previous studies have also suggested higher mortality [49-51] and NEC [52] rates in SGA infants, yet inconclusive as to whether SGA groups have excess risk of severe ROP and SNI $[48,50,52,54]$. The current international study has the largest sample size of any research examining these morbidities and thus has the statistical power to determine small differences in outcome. The smaller than hypothesised outcome difference found between the VLGA and VLBW groups is likely related to improvement of SGA outcomes associated with advances in contemporary clinical practice. The protective effect (negative coefficient) found for vertex presentation for both VLBW and VLGA cohorts suggests other presentations such as breech, transverse or others are associated with a less favourable outcome.

No clinically significant difference in predictive performance was found between the VLGA and VLBW models in this study. The higher SGA percentage within the VLBW cohort did not affect the discrimination power of the VLBW model, suggesting adequate control within the model for the confounding effect present. We propose two explanations for the rejection of our hypothesis. First, in previous VLBW cohort publications, many infants may not have had accurate prenatal gestation assessments, primarily due to substantial limitations in accessibility to early dating ultrasound. In comparison, GA assessment in the three networks of this contemporary study was robust, as all three networks have national healthcare access with nearly universal ultrasound 
examinations of pregnancies. The accurate GA data in both the VLGA and VLBW cohorts improved the accuracy of the models in this study, compared to expectations from previously published VLBW cohort data. Second, the research methodology of this study allowed for inclusion of non-linear relationships, such as the GA and BW zscore interaction. In the VLBW models, this adjusted for growth status and maturity through a balanced shift in the coefficients for BW z-score and GA as well as the negative coefficient in their interaction being the protective confounding effect of growth status and maturity. The noninclusion of these covariates in the VLGA models likely reflects that similar adjustment for SGA infants was not needed, as expected in keeping with the consistent $10 \%$ SGA. Consequently, the large sample sizes of this study combined with sophisticated modelling allowed development of models able to effectively control for confounding and bias, leading to the null findings.

Comparison of the models' usefulness for prediction in the two 'extreme' subsets of VLGA-not-VLBW and VLBW-not-VLGA tests the scope of application. It was found that the power of all models fell when applied to the $<1500$ g BW $\geq 32$-week GA infants, who would almost all be moderately or severely SGA. Predictive power also dropped for both the VLGA and VLBW models when used for CAO prediction in the $\mathrm{BW} \geq 1500 \mathrm{~g}$ and $\mathrm{GA}<32$ week subset, but remained excellent for mortality prediction. This clearly confirms that both mortality prediction models perform well for an extreme cohort containing no SGA infants [23]. The finding that the CAO prediction model did not perform as well as expected could indicate increased vulnerability of large for GA infants to morbidities. The findings suggest that separate prediction models may need to be developed for infants on the extreme subsets of established cohorts where there is a high proportion of SGA or LGA infants, as standard statistical modelling derived from either VLGA or VLBW may not be appropriate for use.

This study is reliable due to its large sample size of 31,940 , and the population based nature of the data [55]. Relative to the size of the samples there were very few missing or incorrect data, attesting to the high quality of the originating databases. The international collaboration allowed validation of study findings across three neonatal networks, and was made more effective by choosing networks with similar databases. Additionally, Canada, Sweden and Australia/New Zealand have high coverage with early dating ultrasound and thus accurate GA data, in contrast to other studies that have combined last menstrual period and ultrasound dating, thus applying GA estimations that differ by up to 3 weeks $[8,56]$. Through the examination of both mortality and CAO, this study will be useful as survival at lower GA becomes possible and prediction of survival without major morbidities becomes increasingly vital.
This study was limited to the analysis of variables collected uniformly across all network databases for the complete study period, but the similarity and quality of the network databases included curtailed the effect of this limitation. The observational, retrospective design meant that no causal mechanisms can be imputed..

The conclusion that VLBW cohorts perform as well as VLGA cohorts for prediction of mortality and morbidity will have ramifications at the international and population levels. Comparison of population outcome may now be considered valid regardless of the cohorting method used to obtain data, providing both GA and BW z scores are included in analytic models. This represents a major advancement in international benchmarking. This study also provides evidence to justify the continued use of BW-based cohorting in some nations provided accurate GA data are included. A further corollary of this study is clarification of the literature on VLGA and VLBW neonates. The findings elucidate both the external validity of research based on one cohort for application to the other, and the appropriateness of comparing data or conclusions based on disparately cohorted groups.

Further investigation is warranted into whether the findings of this study can be extrapolated to countries with poorer access to antenatal care, in particular early dating ultrasound, and hence less accurate GA estimation. Moreover, further studies should compare predictive power for longer-term outcomes such as neurodevelopment, where differing SGA proportions would be expected to have greater effect.

\section{Conclusion}

Outcomes of high-risk neonates are commonly reported either by gestational age or by birth weight. Compared to gestation-based cohorts, birth weight cohorts are more prone to selection bias toward small-for-gestational age infants, who are at high risk of adverse outcomes. However, this study found cohorts based on VLBW or VLGA were equally effective when used to generate prediction models for mortality and morbidity across the three national neonatal networks of Australia/New Zealand, Canada and Sweden. Both models had excellent predictive power when applied to VLGA and VLBW groups, illustrating that either model is appropriate for use, provided GA and $\mathrm{BW}$ parameters included in the modeling have been collected well. Neither model performed well at the extremes of BW for GA, particularly where it contained a high proportion of SGA or LGA infants. The findings of this study may facilitate comparisons for international benchmarking and subsequent quality improvement, and provides support for continued adherence to BW-based cohorting in appropriately designed population studies. 


\section{Additional files}

Additional file 1: Table S1. Consensus definitions of important variables. Definitions of neonatal outcomes with consensus definitions agreed upon by the CNN, ANZNN and SNQ. Table S2: Stratified outcomes between networks. (a): Unadjusted perinatal risks, mortality and major neonatal morbidities among SNQ, ANZNN and CNN infants during 20082011 by gestational age groups. (b): Unadjusted perinatal risks, mortality and major neonatal morbidities among SNQ, ANZNN and CNN infants during 2008-2011 by birth weight groups. Table S3: Cross comparison of predictive power of very low birth weight (VLBW) and very low gestational age (VLGA) based models. Table S4: Comparisons of infant and perinatal characteristics and neonatal outcomes among networks (ANZNN, CNN, SNQ) for the 2 extreme components of the very low gestational age cohort and very low birth weight cohort 2008-2011 admissions [25-27, 57-59]. (DOC $174 \mathrm{~kb})$

\section{Abbreviations}

AGA: Appropriate for gestational age; ANZNN: Australia and New Zealand Neonatal Network; AUC: Area under the curve; BW: Birth weight; CAO: Composite adverse outcome; CLD: Chronic lung disease; CNN: Canadian Neonatal Network; GA: Gestational age; IVH: Intraventricular haemorrhage; NEC: Necrotising enterocolitis; NI: Nosocomial infection; NICU: Neonatal intensive care unit; PVL: Periventricular leukomalacia; ROC: Receiver operating characteristic; ROP: Retinopathy of prematurity; SD: Standard deviation; SGA: Small for gestational age; SNI: Severe neurological injury; SNQ: Swedish Neonatal Quality Register; VLBW: Very low birth weight; VLGA: Very low gestational age

\section{Acknowledgements}

The authors wish to thank all the diligent data managers and extractors of all participating hospitals of the 3 neonatal networks in prospectively collecting the relevant clinical data for their respective network databases. Advisory Council Members of ANZNN (* denotes ANZNN Executives). Peter Marshall (Flinders Medical Centre, SA), Paul Craven (John Hunter Hospital, NSW), Karen Simmer* (King Edward Memorial and Princess Margaret Hospitals, WA), Jacqueline Stack (Liverpool Hospital, NSW), David Knight (Mater Mother's Hospital, QLD), Andrew Watkins (Mercy Hospital for Women, VIC), Andrew Ramsden, Kenneth Tan*, Kaye Bawden* (Monash Medical Centre, VIC), Lyn Downe, Vjay Singde (Nepean Hospital, NSW), Michael Stewart (Newborn Emergency Transport Service, VIC), Andrew Berry (NSW Newborn \& Paediatric Emergency Transport Service), Rod Hunt (Royal Children's Hospital, VIC), Charles Kilburn (Royal Darwin Hospital, NT), Peter Dargaville (Royal Hobart Hospital, TAS), Kei Lui* (Royal Hospital for Women, NSW), Mary Paradisis (Royal North Shore Hospital, NSW), Nick Evans*, Shelley Reid* (Royal Prince Alfred Hospital, NSW), David Cartwright* (Royal Women's Hospital, QLD), Carl Kuschel, Lex Doyle, (Royal Women's Hospital, VIC), Andrew Numa (Sydney Children's Hospital, NSW), Zsuzsoka Kecskes (The Canberra Hospital, ACT), Nadia Badawi (The Children's Hospital at Westmead, NSW), Guan Koh* (The Townsville Hospital, QLD), Steven Resnick (Western Australia Neonatal Transport Service), Mark Tracy, William Tarnow-Mordi* (Westmead Hospital, NSW), Chad Andersen (Women's \& Children's Hospital, SA). New Zealand: Nicola Austin (Christchurch Women's Hospital), Brian Darlow* (Christchurch School of Medicine), Roland Broadbent* (Dunedin Hospital), Jenny Corban* (Hawkes Bay Hospital), Lindsay Mildenhall (Middlemore Hospital), Malcolm Battin (National Women's Hospital), David Bourchier (Waikato Hospital), Vaughan Richardson (Wellington Women's Hospital). ANZNN executives not contributing hospital data: Ross Haslam* Chair of the executives, Georgina Chambers* (National Perinatal Statistics and Epidemiology Unit, University of New South Wales); Victor Samual Rajadurai*, (KK Hospital, Singapore).

\section{CNN Site Investigators}

Shoo K Lee (Chairman, Canadian Neonatal Network; Sick Kids Hospital, Toronto, ON); Prakesh S Shah (Director, Canadian Neonatal Network; Mount Sinai Hospital, Toronto, ON); Andrzej Kajetanowicz (Cape Breton Regional Hospital, Sydney, NS); Anne Synnes (Children's and Women's Health Centre of British Columbia, Vancouver, BC); Nicole Rouvinez-Bouali (Children's Hospital of Eastern Ontario, Ottawa, ON); Bruno Piedboeuf (Centre Hospitalier Universitaire de Quebec, Sainte Foy, QC); Valerie Bertelle (Centre Hospitalier Universitaire de Sherbrooke, Fleurimont, QC); Barbara Bulleid (Dr. Everett
Chalmers Regional Hospital, Fredericton, NB); Wendy Yee (Foothills Medical Centre, Calgary, AB); Sandesh Shivananda (Hamilton Health Sciences Centre, Hamilton, ON); Kyong-Soon Lee (Hospital for Sick Children, Toronto, ON); Mary Seshia (Health Sciences Centre, Winnipeg, MB); Keith Barrington, Francine Lefebvre (Hospital Sainte-Justine, Montreal, QC); Douglas McMillan (IWK Health Centre, Halifax, NS); Wayne Andrews (Janeway Children's Health and Rehabilitation Centre, St Johns, NL); Lajos Kovacs (Jewish General Hospital, Montreal, QC); Kimberly Dow (Kingston General Hospital, Kingston, ON); Orlando da Silva (London Health Science Centre; London, ON); Patricia Riley (Montreal Children's Hospital, Montreal, QC); Prakeshkumar Shah (Mount Sinai Hospital, Toronto, ON); Abraham Peliowski/Khalid Aziz (Royal Alexandra Hospital, Edmonton, AB); Zenon Cieslak (Royal Columbian Hospital, New Westminster, BC); Zarin Kalapesi (Regina General Hospital, Regina, SK); Koravangattu Sankaran (Royal University Hospital, Saskatoon, SK); Daniel Faucher (Royal Victoria Hospital, Montreal, QC); Ruben Alvaro (St Boniface General Hospital, Winnipeg, MB); Roderick Canning (The Moncton Hospital, Moncton, NB); Cecil Ojah/Luis Monterrosa (St John Regional Hospital, St John, NB); Michael Dunn (Sunnybrook Health Sciences Centre, Toronto, ON); Todd Sorokan (Surrey Memorial Hospital, Surrey, BC); Adele Harrison (Victoria General Hospital, Victoria, BC) and Chuks Nwaesei /Mohammed Adie (Windsor Regional Hospital, Windsor, ON).

\section{SNO Site Investigators:}

Stellan Håkansson (Chairman, Swedish Neonatal Quality Register; Norrlands Universitetssjukhus, Umeå); Gunnar Sjörs (Co-Director, Swedish Neonatal Quality Register; Akademiska Sjukhuset, Uppsala); Niklas Segerdahl (Borås lasarett, Borås); Tarek Morad (Mälarsjukhuset, Eskilstuna); Stefan Morén (Falu lasarett, Falun); Åke Stenberg (Gällivare sjukhus, Gällivare); Christer Simonsson (Länssjukhuset Gävle-Sandviken, Gävle); Lennart Stigsson (Östra sjukhuset, Göteborg); Jens Ladekjaer Christensen (Halmstads länssjukhus, Halmstad); Lars Åmasn (Hudiksvalls sjukhus, Hudiksvall); Fredrik Ingemanson (Länssjukhuset Ryhov, Jönköping); Laura Österdal (Länssjukhuset, Kalmar); Karl-Gustav Ellström (Centralsjukhuset, Karlstad); Thomas Abrahamsson (Universtitetssjukhuset, Linköping); Ingela Heimdahl (Sunderby sjukhus, Luleå); Tomas Hägg (Vrinnevisjukhus, Norrköping); Anna Hedlund (Skellefteå lasarett, Skellefteå); Ellen Elisabeth Lund (Kärnsjukhuset, Skövde); Björn Westrup (Karolinska sjukhuset, Stockholm); Ihsan Sarman (Södersjukhuset, Stockholm); Anna Stakkestad Jobe (NÄL, Trollhättan); Magnus Fredsriksson (Visby lasarett, Visby); Anders Palm (Västerviks sjukhus, Västervik); Birger Malmström (Centrallasarettet, Västerås); Eva Lindberg (Universitetssjukhuset, Örebro); Owe Ljungdahl, (Örnsköldsviks sjukhus, Örnsköldsvik) and Kerstin Eriksson (Östersunds sjukhus, Östersund).

\section{Funding}

This study and the Australian and New Zealand Neonatal Network were supported from the ANZNN members' contribution and in part by a grant from Leslie Steven Grant for Newborn Care, Sydney Children's Hospital Foundation, Australia, and Royal Hospital for Women Foundation, New South Wales, Australia. The Canadian Neonatal Network is supported by funding from the Canadian Institutes of Health Research and from the Ministry of Health and Long-Term Care, Ontario, Canada for infrastructure support to the Maternal-Infant Care Research Centre, which is the coordinating center for the network. Additional funding was provided by individual participating hospitals. The Swedish Neonatal Quality Register is supported by the Swedish Association of Local Authorities and Regions, with additional funding by the participating hospitals. The iNeo collaboration at the Mother-Infant Care Research Centre, Toronto conducted the data collation and analyses for this study, is funded by the Canadian Institute of Health Research.

\section{Availability of data and materials}

The datasets generated during the current study are not publicly available. Supplying individual raw data outside the network research framework is in conflict with the applicable legislation of all three participating countries. The Research Ethics Committee approval requires all electronic research data, including de-identified patient data, to be stored in designated password protected computers within the facility of the researchers.

\section{Authors' contributions}

LIMKS conducted the literature review, participated in review of data analysis and interpretation of results and prepared the final manuscript. $\mathrm{KL}$ conceptualised the study and design, contributed to the interpretation of results and critically reviewed the final manuscript. PSS contributed to the 
conception and study design, coordinated transfer of Canadian Neonatal Network data, contributed to review and interpretation of results and critically reviewed the final manuscript. GS contributed to the conception and study design, co-ordinated transfer of Swedish Neonatal Quality Register data, contributed to the review and interpretation of results and critically reviewed the final manuscript. XYY designed the statistical analytic approach, carried out the statistical modelling and analysis and critically reviewed the final manuscript. YAW reviewed statistical modelling and analysis and critically reviewed the manuscript. SSWC was involved in transfer and data checking of ANZNN data and contributed to the analytic approach. SKL contributed to the study conception and was involved in review of statistical analyses. BAD contributed to the conception of the study, collaborated on study design, and critically reviewed the final manuscript. SH contributed to the conception of the study and critically reviewed the final manuscript. All authors read and approved the final version of the manuscript.

\section{Authors information}

List of site investigators and hospitals contributing data to the iNEO project.

\section{Ethics approval and consent to participate}

Study was approved by the South Eastern Sydney Local Health District Human Research Ethics Committee HREC reference number 13/041. Consent not applicable for de-identified data collection in aggregated report and analysis.

\section{Consent for publication}

Not applicable.

\section{Competing interest}

The authors have no competing interest to disclose. The authors have no financial relationships relevant to this article to disclose.

\section{Publisher's Note}

Springer Nature remains neutral with regard to jurisdictional claims in published maps and institutional affiliations.

\section{Author details \\ ${ }^{1}$ Faculty of Health Science, University of Technology Sydney, Sydney, NSW, Australia. ${ }^{2}$ Department of Pediatrics, Mount Sinai Hospital and University of Toronto, Toronto, ON, Canada. ${ }^{3}$ Maternal Infant Care Research Centre, Mount Sinai Hospital, Toronto, ON, Canada. ${ }^{4}$ Uppsala University, Uppsala, Sweden. ${ }^{5}$ Department of Paediatrics, University of Otago, Christchurch, New Zealand. ${ }^{6}$ Umeå University Hospital, Umeå, Sweden. ${ }^{7}$ Department of Newborn Care, Royal Hospital for Women, Barker St, Sydney, NSW 2031, Australia.}

Received: 7 December 2015 Accepted: 5 July 2017

Published online: 14 July 2017

\section{References}

1. Gilbert WM, Nesbitt TS, Danielsen B. The cost of prematurity: quantification by gestational age and birth weight. Obstet Gynecol. 2003;102(3):488-92.

2. Allen MC. Preterm outcomes research: a critical component of neonatal intensive care. Ment Retard Dev Disabil Res Rev. 2002:8(4):221-33.

3. Mohangoo AD. Blondel Ba, Gissler M, Velebil P, Macfarlane a, Zeitlin J: international comparisons of fetal and neonatal mortality rates in highincome countries: should exclusion thresholds be based on birth weight or gestational age? PLoS One. 2013:8(5):e64869.

4. Larroque B, Ancel PY, Marret S, Marchand L, Andre M, Arnaud C, Pierrat V, Roze JC, Messer J, Thiriez G, et al. Neurodevelopmental disabilities and special care of 5-year-old children born before 33 weeks of gestation (the EPIPAGE study): a longitudinal cohort study. Lancet. 2008;371(9615):813-20.

5. Smith LK, Draper ES, Field D. Long-term outcome for the tiniest or most immature babies: survival rates. Semin Fetal Neonatal Med. 2014;19(2):72-7.

6. Arnold CC, Kramer MS, Hobbs CA, McLean FH, Usher RH. Very low birth weight: a problematic cohort for epidemiologic studies of very small or immature neonates. Am J Epidem. 1991;134(6):604-13.

7. Blair $E$. The undesirable consequences of controlling for birth weight in perinatal epidemiological studies. J Epidem Community Health. 1996; 50(5):559-63.
8. Ananth CV, Platt RW. Reexamining the effects of gestational age, fetal growth, and maternal smoking on neonatal mortality. BMC Preg Childbirth. 2004;4(1):22

9. Kamoji VM, Dorling JS, Manktelow BN, Draper ES, Field DJ. Extremely growthretarded infants: is there a viability centile? Pediatrics. 2006;118(2):758-63.

10. Ruegger C, Hegglin M, Adams M, Bucher HU. Population based trends in mortality, morbidity and treatment for very preterm-and very low birth weight infants over 12 years. BMC Pediatr. 2012;12(1):17.

11. Kusuda S, Fujimura M, Sakuma I, Aotani H, Kabe K, Itani Y, Ichiba H, Matsunami K, Nishida H. Morbidity and mortality of infants with very low birth weight in Japan: center variation. Pediatrics. 2006;118(4):e1130-8.

12. Munck P, Niemi P, Lapinleimu H, Lehtonen L, Haataja L. Stability of cognitive outcome from 2 to 5 years of age in very low birth weight children. Pediatrics. 2012;129(3):503-8

13. Pollack MM, Koch MA, Bartel DA, Rapoport I, Dhanireddy R, ElMohandes AA, Harkavy K, Subramanian KS. A comparison of neonatal mortality risk prediction models in very low birth weight infants. Pediatrics. 2000;105(5):1051-7.

14. Verloove-Vanhorick SP, Verwey RA, Ebeling MC, Brand R, Ruys JH Mortality in very preterm and very low birth weight infants according to place of birth and level of care: results of a national collaborative survey of preterm and very low birth weight infants in The Netherlands. Pediatrics. 1988;81(3):404-11.

15. Vieux R, Fresson J, Hascoet J-M, Blondel B, Truffert P, Roze J-C, Matis J, Thiriez G, Arnaud C, Marpeau L. Improving perinatal regionalization by predicting neonatal intensive care requirements of preterm infants: an EPIPAGE-based cohort study. Pediatrics. 2006;118(1):84-90.

16. Hagan $\mathrm{R}$, Benninger $\mathrm{H}$, Chiffings $\mathrm{D}$, Evans $\mathrm{S}$, French N. Very preterm birth-a regional study. Part 2: the very preterm infant. Br J Obstet Gynaecol. 1996; 106:239-45.

17. Verloove-Vanhorick SP, Verwey R, Brand R, Bennebroek Gravenhorst J, Keirse $M$, Ruys J. Neonatal mortality risk in relation to gestational age and birthweight: results of a national survey of preterm and very-lowbirthweight infants in the Netherlands. Lancet. 1986:327(8472):55-7.

18. World Health Organization Expert Committee on Maternal Child Health. Public health aspects of low birth weight, third report of the committee, Technical report series no. 217. Geneva: W.H.O; 1961.

19. Helwich E, Wojkowska-Mach J, Borszewska-Kornacka M, Gadzinowski J, Gulczynska E, Kordek A, Pawlik D, Szczapa J, Domanska J, Klamka J, et al. Epidemiology of infections in very low birth weight infants. Polish neonatology network reasearch. Med Wieku Rozwoj. 2013;17(3):224-31.

20. Coggins SA, Wynn JL, Hill ML, Slaughter JC, Ozdas-Weitkamp A, Jalloh O, Waitman LR, Carnevale RJ, Weitkamp JH. Use of a computerized C-reactive protein (CRP) based sepsis evaluation in very low birth weight (VLBW) infants: a five-year experience. PLoS One. 2013:8(11):e78602.

21. Meier PP, Bode L. Health, nutrition, and cost outcomes of human milk feedings for very low birthweight infants. Adv Nutr. 2013:4(6):670-1.

22. Dobbins TA, Sullivan EA, Roberts CL, Simpson JM. Australian national birthweight percentiles by sex and gestational age, 1998-2007. Med J Australia. 2012;197(5):291

23. Kramer MS, Platt RW, Wen SW, Joseph K, Allen A, Abrahamowicz M. Blondel $\mathrm{Ba}, \mathrm{Br} \sqrt{ } \odot \mathrm{art} \mathrm{Gr}$ : a new and improved population-based Canadian reference for birth weight for gestational age. Pediatrics. 2001:108(2):e35.

24. Marsal K, Persson P, Larsen T, Lilja H, Selbing A, Sultan B. Intrauterine growth curves based on ultrasonically estimated foetal weights. Acta Paediatr. 1996; 85(7):843-8.

25. Papile L-A, Burstein J, Burstein R, Koffler $\mathrm{H}$. Incidence and evolution of subependymal and intraventricular hemorrhage: a study of infants with birth weights less than 1,500 gm. J Pediatr. 1978;92(4):529-34.

26. ICoRoP. An international classification of retinopathy of prematurity. Pediatrics. 1984;74(1):127-33.

27. Bell MJ, Ternberg JL, Feigin RD, Keating JP, Marshall R, Barton L, Brotherton T. Neonatal necrotizing enterocolitis. Therapeutic decisions based upon clinical staging. Annals Surg. 1978;187(1):1.

28. Sax H, Pittet D. Interhospital differences in nosocomial infection rates: importance of case-mix adjustment. Arch Internal Med. 2002;162(21):2437.

29. Pollack MM, Ruttimann UE, Getson PR. Pediatric risk of mortality (PRISM) score. Crit Care Med. 1988:16(11):1110-6.

30. Cole TJ, Hey E, Richmond S. The PREM score: a graphical tool for predicting survival in very preterm births. Arch Dis Childhood-Fetal and Neonatal Edition. 2010;95(1):F14-9. 
31. Shah PS, Xiang YY, Synnes A, Rouvinez-Bouali N, Yee W, Lee SK. Prediction of survival without morbidity for infants born at under 33 weeks gestational age: a user-friendly graphical tool. Arch Dis Childhood-Fetal and Neonatal Edition. 2012;97(2):F110-5.

32. Chiang MF, Starren J, Du YE, Keenan JD, Schiff WM, Barile GR, Li J, Johnson RA, Hess DJ, Flynn JT. Remote image based retinopathy of prematurity diagnosis: a receiver operating characteristic analysis of accuracy. Brit J Ophthal. 2006;90(10):1292-6.

33. Manktelow BN, Draper ES, Field DJ. Predicting neonatal mortality among very preterm infants: a comparison of three versions of the CRIB score. Arch Dis Childhood-Fetal and Neonatal Edition. 2010;95(1):F9-F13.

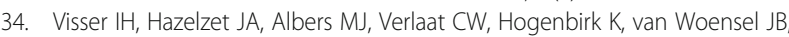
van Heerde M, van Waardenburg DA, Jansen NJ, Steyerberg EW. Mortality prediction models for pediatric intensive care: comparison of overall and subgroup specific performance. Intens Care Med. 2013:1-9.

35. Hosmer Jr DW, Lemeshow S. Applied logistic regression:second edition, Section 5.2.4. A Wiley-Interscience Publication. New York: Wiley. 2000. p. 147

36. Hosmer Jr DW, Lemeshow S. Applied logistic regression: second edition, Section 5.2.2. A Wiley-Interscience Publication. New York: Wiley. 2000. p. 147

37. SAS Institute. SAS software. 9.3 ed. Cary, NC: SAS Institute; 2011.

38. The R Project for Statistical Computing: Version 2.10.15. http://www.rproject.org. Accessed 10 Apr 2015.

39. Lubchenco L, Delivoria-Papadopoulos M, Searls D. Long-term follow-up studies of prematurely born infants. II. Influence of birth weight and gestational age on sequelae. J Pediatr. 1972;80(3):509-12.

40. Lubchenco LO, Searls D, Brazie J. Neonatal mortality rate: relationship to birth weight and gestational age. J Pediatr. 1972;81(4):814-22.

41. Batton DG. Antenatal counseling regarding resuscitation at an extremely low gestational age. Pediatr. 2009;124(1):422-7.

42. Wilcox AJ, Skjaerven R. Birth weight and perinatal mortality: the effect of gestational age. Am J Public Health. 1992;82(3):378-82.

43. Verloove-Vanhorick S, Van Zeben-van der Aa D, Verwey R, Brand R, Ruys J. The male disadvantage in very low birthweight infants: does it really exist? Eur J Pediatr. 1989;149(3):197-202

44. Schmidt B, Asztalos EV, Roberts RS, Robertson CM, Sauve RS, Whitfield MF. Impact of bronchopulmonary dysplasia, brain injury, and severe retinopathy on the outcome of extremely low-birth-weight infants at 18 months. JAMA. 2003;289(9):1124-9.

45. Greenwood S, Abdel-Latif ME, Bajuk B, Lui K. Can the early condition at admission of a high-risk infant aid in the prediction of mortality and poor neurodevelopmental outcome? A population study in Australia. J Paediatr Child Health. 2012;48(7):588-95.

46. de Waal CG, Weisglas-Kuperus N, van Goudoever JB, Walther FJ, Vermeulen $M$, van Wassenaer A. Mortality, neonatal morbidity and two year follow-up of extremely preterm infants born in the Netherlands in 2007. PLoS One. 2012;7(7):e41302.

47. Faroogi A, Haggloff B, Sedin G, Serenius F. Impact at age 11 years of major neonatal morbidities in children born extremely preterm. Pediatrics. 2011; 127(5):e1247-57

48. Bartels D, Kreienbrock L, Dammann O, Wenzlaff P, Poets C. Population based study on the outcome of small for gestational age newborns. Arch Dis Childhood-Fetal and Neonatal Edition. 2005;90(1):F53-9.

49. Piper JM, Xenakis EM, McFARLAND M, Elliott BD, Berkus MD, Langer O. Do growth-retarded premature infants have different rates of perinatal morbidity and mortality than appropriately grown premature infants? Obstet Gynecol. 1996;87(2):169-74.

50. Troger B, Gopel W, Faust K, Muller T, Jorch G, Felderhoff-Moser U, Gortner L, Heitmann F, Hoehn T, Kribs A. Risk for late-onset blood-culture proven sepsis in very-low-birth weight infants born small for gestational age: a large multi-center study from the German neonatal network. Pediatr Infect Dis J. 2014;33(3):238-43.

51. Lal MK, Manktelow BN, Draper ES, Field DJ. Chronic lung disease of prematurity and intrauterine growth retardation: a population-based study. Pediatrics. 2003;111(3):483-7.

52. Wold SW, Sommerfelt K, Reigstad H, Ronnestad A, Medbo S, Farstad T, Kaaresen PI, Stoen R, Leversen KT, Irgens L. Neonatal mortality and morbidity in extremely preterm small for gestational age infants: a population based study. Arch Dis Childhood-Fetal and Neonatal Edition. 2009;94(5):F363-7.

53. Shima Y, Kumasaka S, Migita M: Perinatal risk factors for adverse long,Aeterm pulmonary outcomes in premature infants: comparison of different definitions of bronchopulmonary dysplasia/chronic lung disease. Pediatr Int. 2013;55(5): 578-81.

54. Bardin C, Zelkowitz P, Papageorgiou A. Outcome of small-for-gestational age and appropriate-for-gestational age infants born before 27 weeks of gestation. Pediatrics. 1997;100(2):e4.

55. Draper ES, Manktelow B, Field DJ, James D. Prediction of survival for preterm births by weight and gestational age: retrospective population based study. BMJ. 1999;319(7217):1093-7.

56. Johansson S, Montgomery SM, Ekbom A, Olausson PO, Granath F, Norman M, Cnattingius S. Preterm delivery, level of care, and infant death in Sweden: a population-based study. Pediatr. 2004:113(5):1230-5.

57. The Canadian Neonatal Network. Abstractor's manual. In: Abstractor's manual. v2.0.0 ed; 2012

58. ANZNN: ANZNN data dictionary. In: ANZNN data dictionary: definitions for audit. 2011/2012.

59. Serenius FS, G: Anvandarmanual PNQ 2011. In: Anvarndarmanual PNQ:S Edited by Styrgrupp Ps, 9 edn; 2011.

\section{Submit your next manuscript to BioMed Central and we will help you at every step:}

- We accept pre-submission inquiries

- Our selector tool helps you to find the most relevant journal

- We provide round the clock customer support

- Convenient online submission

- Thorough peer review

- Inclusion in PubMed and all major indexing services

- Maximum visibility for your research

Submit your manuscript at www.biomedcentral.com/submit 